\title{
Synthesis and Characterization of CuPc-PEPC Composite Thin Films and Photovoltaic Devices by Drop Casting Method
}

\author{
TAMARA POTLOG ${ }^{1 *}$, VADIM FURTUNA ${ }^{1}$, ION LUNGU ${ }^{1}$, STEFAN ROBU ${ }^{2}$, \\ GALINA DRAGALINA ${ }^{2}$, ANA POPUSOI ${ }^{2}$, PETRU BULMAGA ${ }^{2}$ \\ ${ }^{1}$ Physics Department and Engineering, Moldova State University, 60, A. Mateevici Str. MD-2009, Chisinau, Moldova \\ ${ }^{2}$ The Faculty of Chemistry and Chemical Technology, Moldova State University, 60, A. Mateevici Str. MD-2009, Chisinau, \\ Moldova
}

\begin{abstract}
Using a drop casting method, stronger absorbent and photosensitive composite thin films based on a copper-phthalocyanine $(\mathrm{CuPc})$ oligomer and a poly (N-epoxypropylcarbazole) (PEPC) copolymer were developed. Morphology, structural behavior and optical properties of CuPc:PEPC composite thin films have been studied using scanning electron microscopy (SEM), X-ray diffraction (XRD) and UV-VIS spectroscopy. The SEM images of pure CuPc organic thin films show the formation of some elongated shapes, while the morphology of CuPc:PEPC composite thin films is mainly controlled by the content of CuPc. XRD analysis of the CuPc:PEPC composite thin films reveal good crystallinity and the beta-copper phthalocyanine phase. Study of optical properties of CuPc:PEPC composite thin films after annealing in hydrogen atmosphere show decrease of the average optical transmittance. In addition, the broadening of the absorption bands increases the light harvesting capacity of the composite material for photovoltaic applications.
\end{abstract}

Keywords: CuPc:PEPC composite thin films, morphology, X-ray analysis, absorption, photovoltaic device

\section{Introduction}

In the last years, extensive $R \& D$ efforts have been directed towards various organic semiconductors and their composites to identify materials for organic photovoltaic (OPV) devices. The bulk heterojunction (BHJ) solar cell has become one of the most successful device structures developed in comparison with bilayer constructions. During the last two decades, the performance of the OPV devices have been increased [1-5], particularly through the development of solution-processed BHJ OPV devices [6-8]. In BHJ device structure, the donor is an electron rich conjugated polymer, and the acceptor is a soluble molecular acceptor. The donor and the acceptor are blended to form an unbroken interpenetrating layer, which increases the donor-acceptor (D-A) interfacial area available for the exciton dissociation. Various combinations of donor and acceptor building blocks have been used to generate D-A copolymers with some of them giving excellent performance in BHJ solar cells with fullerene electron acceptors. Donor: acceptor bulk-heterojunction blends have yielded solar cell single-junction efficiencies above $7 \%$ for numerous different polymer: fullerene combinations [9-11] and currently reaching above $10 \%$ [12]. But fullerene-based acceptors have some significant limitations: low absorption in the (500-800) $\mathrm{nm}$ region of the incident solar spectrum $[13,14]$, which limits their ability to harvest photocurrent; limited tunability in terms of spectral absorption; high synthesis costs, especially for their performance in photovoltaic applications [15]. Therefore, one of the challenges in the field of organic photovoltaics is the development of alternatives to the family of fullerene derivatives that are commonly used as acceptor material, but generally do not have a high absorption coefficient. In this paper we propose to replace fullerene-based acceptors with poly(N-epoxypropylcarbazole) (PEPC).

\footnotetext{
*email:tpotlog@gmail.com 
The electrically conductive poly(N-epoxypropylcarbazole) (PEPC) exhibits superb chemical stability in air, water and organic solvents and the PEPC dissolved in trifluoroacetic acid (TFA) has high absorption coefficient $5 \cdot 10^{3} \mathrm{~cm}^{-1}$ in $400-650 \mathrm{~nm}$ wavelength region [16]. The molecular weights of PEPC is between $1500 \mathrm{~g} / \mathrm{mol}$ and $2000 \mathrm{~g} / \mathrm{mol}$ [17]. Among the metal substituted phthalocyanine, copper phthalocyanine have a number of wide-ranging applications as diverse dyes [18], light emitting diodes [19], solar cells [20], etc. Last years a number of capacitive and resistive humidity sensors were investigated on the base of porphyrin, copper phthalocyanine and poly(N-epoxypropylcarbazole) [2123]. Thin films of the PEPC/CuPc nanocomposite deposited by vacuum evaporation by O. Bordian et. al. [24] were used for the development of optical media for holographic storage, electrophotography, photosensors, etc. Metal phthalocyanines are usually highly insoluble and need to be processed by vacuum deposition in the device. According to the $[25,26] \mathrm{CuPc}$ dissolves with high concentrations only in TFA, where it becomes protonated and new bands appear in the absorption spectrum. In this paper we will present some fundamental characterizations like morphology, composition, structural and optical properties of solution-processed CuPc:PEPC composite thin films because polymers containing the carbazole group as for instance poly(N-vinyl) carbazole possess chemical stability, flexibility, thermoplasticity and forms with low molecular organic materials charge transfer complexes that have high photosensitivity or sufficiently high electric conductivity.

\section{Materials and method}

\subsection{Materials and preparation methods}

Commercially available copper phthalocyanine powder was purchased from Sigma Aldrich and was used without further purification. CuPc is little soluble in conventional solvents and ionic liquids. In this paper we dissolved CuPc in 2,4,7-trinitrofluorenone (TNF) and chlorobenzene mixed solvent. CuPc is quite stable (four weeks) in the solution. PEPC however was synthesized in the laboratory using potassium hydroxide $(0.0176 \mathrm{~g}, 0.3 \mathrm{mmol}), 18$-crown-6 $(0.1170 \mathrm{~g}, 0.4 \mathrm{mmol})$ and $8 \mathrm{~mL}$ methanol.

The mixture was heated in vacuum until the volume of the distillate became half of the volume of the original solution. Then a new portion of toluene was added and distilled again. This procedure was repeated four times. The solution was then cooled down to room temperature and filtered. Ionic polymerization is carried out under nitrogen atmosphere. Therefore, polymerization was carried out in a flask equipped with nitrogen purge, in which $8 \mathrm{~mL}$ of the above-mentioned mixture and $0.8741 \mathrm{~g}$ of PEPC were added.

The solution was heated at $120^{\circ} \mathrm{C}$ for $3 \mathrm{~h}$. The resulting polymers were isolated by precipitation in hexane and dried in vacuum at ambient temperature. The molecular weight of prepared PEPC was 1200 $\mathrm{g} / \mathrm{mol}$. PEPC was dissolved in toluene. For the preparation of CuPc:PEPC photosensitive composite thin films the weight ratios such as 1:1 and 2:1 were taken. As a substrate, the glass was used for the preparation of thin films. All the glass substrates were cut into the dimensions of $2 \mathrm{~cm} \times 2 \mathrm{~cm}$. Thin films of PEPC, CuPc and PEPC:CuPC organic composite were prepared by the simplest way of deposition from solution - drop casting method. Drop casting was used to bring more material onto the substrate. The CuPc, PEPC and CuPc:PEPC thin films were drop-casted onto the glass substrate at room temperature. The prepared films are not homogenous in comparison with spin casting and dip coating methods. However, the film is thicker, because the thickness of the film is not limited by centrifugal or gravitational force. After the preparation, the films were dried for $30 \mathrm{~min}$ in air at room temperature, followed by heating for $30 \mathrm{~min}$ at $60^{\circ} \mathrm{C}$ under a hydrogen atmosphere to remove any remaining water and impurities.

\subsection{Analytical methods}

The surface morphology of the CuPc, PEPC, CuPc:PEPC composite thin films was investigated using a FEI Nova NanoSEM 650 Schottky field emission scanning electron microscope (SEM) equipped with an energy dispersive X-ray (EDAX) analyzer operated at $15 \mathrm{kV}$ acceleration voltage. XRD Mater. Plast., 57 (4), 2020, 134-144 
measurements were done using X-ray Brucker D8 Discover diffractometer with $\mathrm{Cu} / 40 \mathrm{kV} / 40 \mathrm{~mA}$ radiation source $(\lambda=1.54056 \AA)$ from $5^{\circ}$ to $60^{\circ} 2 \theta$. For the registration of reflectance and transmittance JASCO V-670 UV-VIS spectrophotometer was used. Fourier Transform Infrared (FTIR) transmission spectra were recorded using a Brucker ALPHA Platinum-ATR spectrophotometer to study chemical composition and bond-dynamics. The spectra were recorded from 4000 to $400 \mathrm{~cm}^{-1}$ at a resolution of 4 $\mathrm{cm}^{-1}$ averaging 24 scans for each measurement. Measurement of the current-voltage curves was performed at room temperature using a 4200-SCS Keithley meter controlled by LabView (National Instruments) with solar simulator calibrated to $100 \mathrm{~mW} \cdot \mathrm{cm}^{-2}$.

\section{Results and discussions}

\subsection{Morphological and Composition of CuPc:PEPC Composite Thin Films}

Figures 1(a) and 2(b) show SEM micrographs of the thin films of the CuPc and PEPC. The SEM image of CuPc film deposited from TNF and chlorobenzene mixed solution at room temperature in Figure 1(a) shows the formation of some elongated shapes. The SEM image of PEPC film in Figure 1(b) reveals a smoother surface with poor crystallinity.

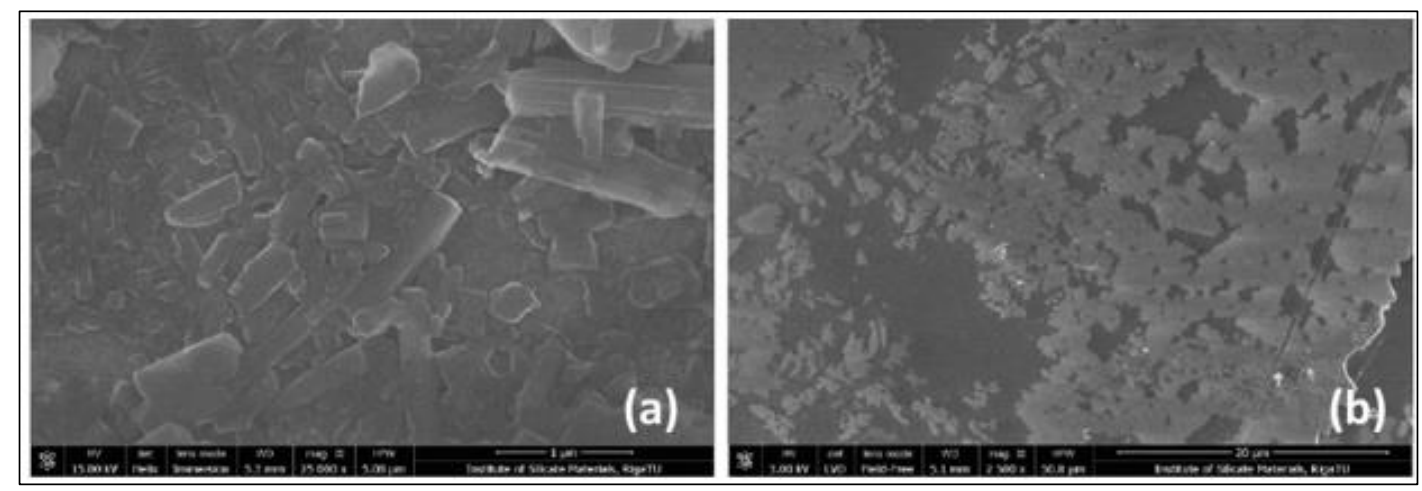

Figure 1. SEM images of CuPc (a) and PEPC thin films (b)

SEM image of 1CuPc:1PEPC composite thin film after annealing in $\mathrm{H}_{2}$ atmosphere $60^{\circ} \mathrm{C}$ during 30 min in Figure 2(a) shows the suppression of elongated shapes and formation of agglomerates of irregular shapes, while SEM image of the 2CuPc:1PEPC composite thin film in Figure 2(b) shows greater uniformity and larger agglomerates without no particular crystal orientations.
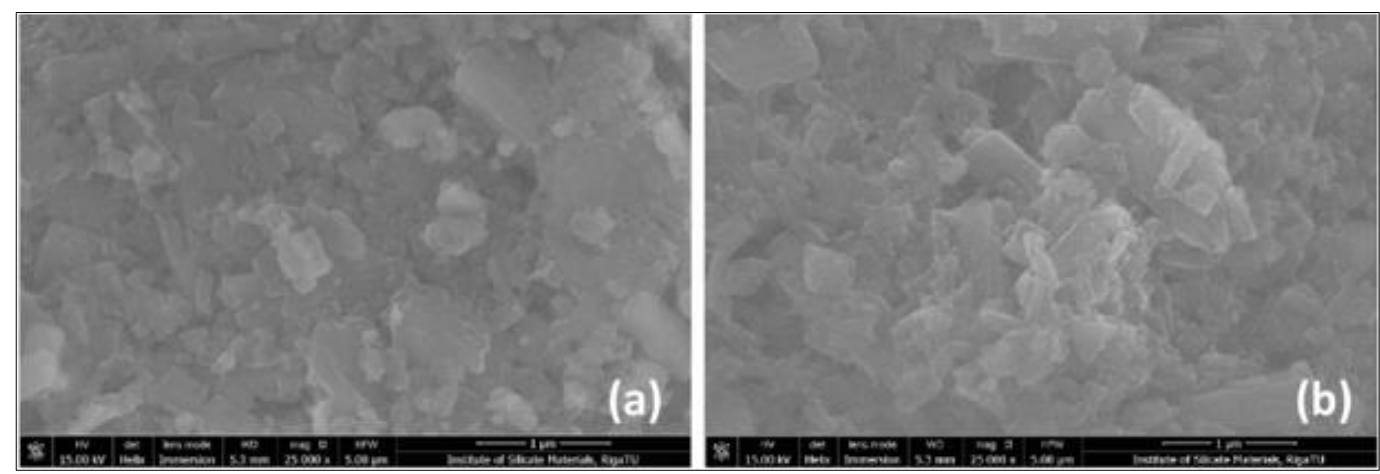

Figure 2. SEM images of 1CuPc:1PEPC (a) and (b) 2CuPc:1PEPC composite thin films

Energy dispersive X-ray analysis (EDAX) was performed for samples of 1CuPc:1PEPC and 2CuPc:1PEPC thin film composites. Figures 3(a) and 3(b) showed the energy dispersive spectra of 1CuPc:1PEPC and 2CuPc:1PEPC thin films, respectively. EDAX spectra of CuPc:PEPC thin films show presence of carbon $(\mathrm{C})$, nitrogen $(\mathrm{N})$ and copper $(\mathrm{Cu})$. The elemental composition analyses of the 
2CuPc:1PEPC thin film composite indicates the changes in elemental composition of the composite and an increase in $\mathrm{Cu}$ with increasing content of $\mathrm{CuPc}$. Other peaks in the energy spectrum are due to glass substrate and ITO coating. The EDAX quantitative results of the above thin films are given in inset tables of the spectra. Hydrogen is not detected in both spectra due to its low atomic weight. Nitrogen in the EDAX spectrum of 2CuPc:1PEPC thin film (Figure 3(b)) is not detected, probably, due to the detection limits of about $1 \mathrm{wt} \%$ and may remain undetected because of overlapping peaks.

\subsection{Structural Properties of CuPc:PEPC Composite Thin Films}

X-ray diffractograms of CuPc powder and PEPC thin films are presented in Figure 4 and Figure 5. Copper phthalocyanine in powder form exhibits a crystalline nature. Indexing of CuPc powder is carried out by comparing the diffractogram with the Joint Committee on Powder Diffraction Studies (JCPDS, File No. 11-893) data. It is confirmed that the source material is $\mathrm{CuPc}$ and its structure is monoclinic with different lattice parameters: $a=10.1379 \AA ; b=12.5510 \AA ; c=8.7537 \AA$ [27]. The diffraction patterns of the PEPC films with different thicknesses shows higher amorphous character with broader peak. X-ray diffraction pattern of CuPc:PEPC composite thin films before and after annealing in $\mathrm{H}_{2}$ atmosphere at $60^{\circ} \mathrm{C}$ during $30 \mathrm{~min}$ are shown in Figure 6.

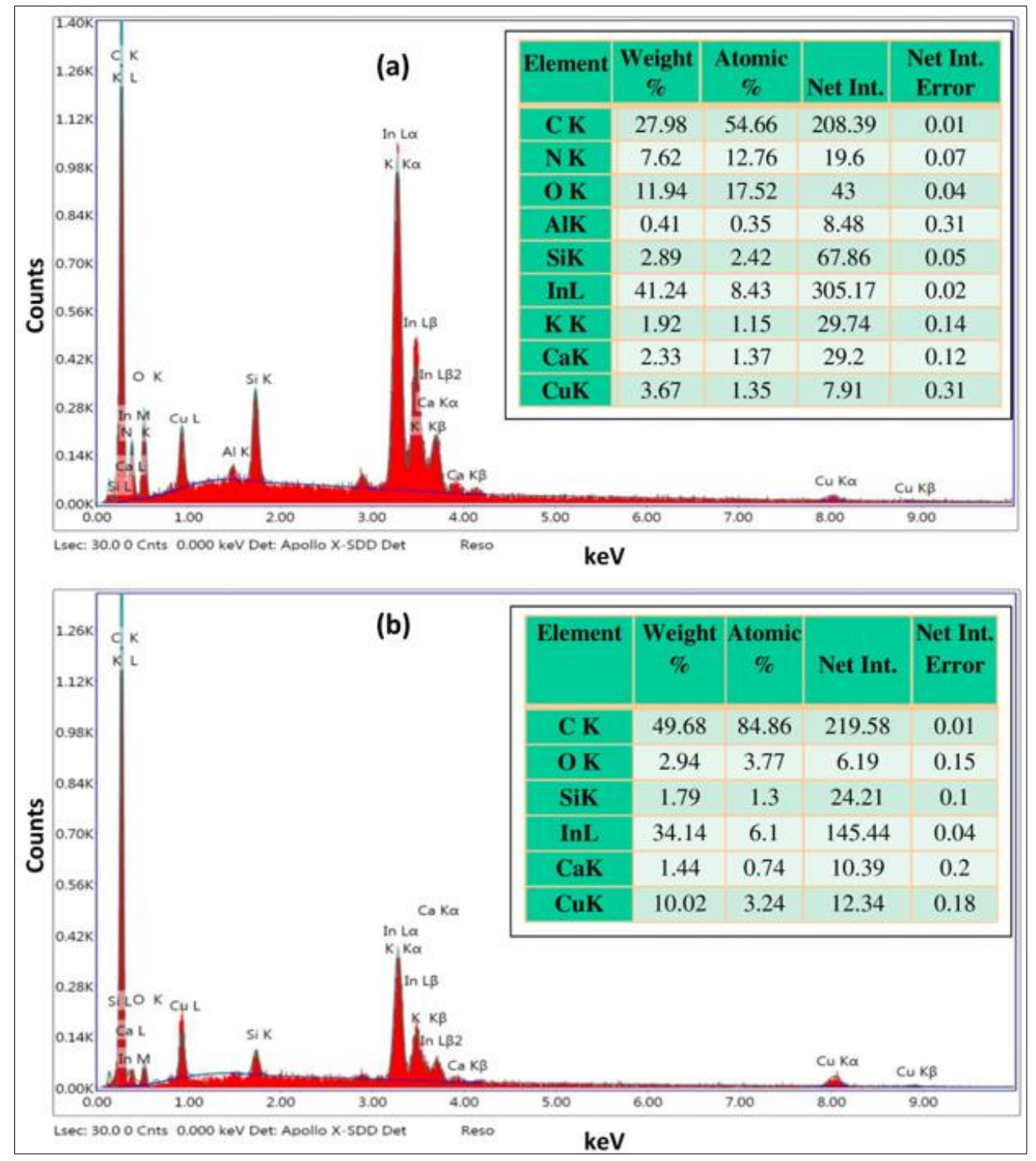

Figure 3. EDAX spectra of drop casted 1CuPc:1PEPC (a) and 2CuPc:1PEPC (b) composite thin films 
As one can see, from Figure 6 the number of diffraction peaks in comparison with CuPc powder reduces, and annealing in $\mathrm{H}_{2}$ atmosphere at $60^{\circ} \mathrm{C}$ increases its intensity. In addition, a shift in the $\mathrm{CuPc}$ peaks was identified with increasing of $\mathrm{CuPc}$ composition. The sharp diffraction peaks indicate the good crystallinity of the prepared films. XRD study of the CuPc:PEPC composite thin films reveals only the beta-copper phthalocyanine phase. The crystal structure of the $\beta$-form is monoclinic. The $\beta$-form is the thermodynamically stable one [17]. Using the peak positions from the XRD pattern in Rigaku software program, the crystal structure and lattice parameters were determined and given in Table 1.

Table 1 shows that the grain sizes are reduced after annealing in the case of 1CuPc:1PEPC thin film, while in the case of $2 \mathrm{CuPc}: 1 \mathrm{PEPC}$ the grain size increases that represents better crystallite structures of the films. This could be attributed to the density increasing with increasing $\mathrm{CuPc}$ concentration. The higher values of estimated strain in our case indicate polycrystalline nature of the films.

Table 1. Structural parameters of CuPc:PEPC composite thin films

\begin{tabular}{|c|c|c|c|c|c|c|c|}
\hline Sample & $\begin{array}{c}\text { 2-theta } \\
\text { (degree) }\end{array}$ & $\begin{array}{l}\text { Height } \\
\text { (cps) }\end{array}$ & D (ang.) & $\begin{array}{c}\text { a } \\
\text { (ang) }\end{array}$ & b (ang) & $\begin{array}{c}c \\
\text { (ang) }\end{array}$ & $\begin{array}{c}\text { Strain, } \\
(\%)\end{array}$ \\
\hline \multirow[t]{2}{*}{ 1CuPc:1PEPC untreated } & 7.054 & 327363 & 2141 & \multirow{2}{*}{14.6266} & \multirow[t]{2}{*}{4.6897} & \multirow{2}{*}{17.2931} & \multirow{2}{*}{0.142} \\
\hline & 9.227 & 231752 & 1668 & & & & \\
\hline \multirow[t]{2}{*}{ 1CuPc:1PEPC treated } & 7.053 & 470395 & 1885 & \multirow[t]{2}{*}{14.6408} & \multirow[t]{2}{*}{4.6943} & \multirow{2}{*}{17.3098} & \multirow[t]{2}{*}{0.16} \\
\hline & 9.223 & 328818 & 1546 & & & & \\
\hline \multirow[t]{2}{*}{ 2CuPc:1PEPC untreated } & 7.126 & 381393 & 1817 & \multirow{2}{*}{14.5322} & \multirow{2}{*}{4.6595} & \multirow{2}{*}{17.1814} & \multirow{2}{*}{0.096} \\
\hline & 9.291 & 324609 & 1693 & & & & \\
\hline \multirow[t]{2}{*}{ 2CuPc:1PEPC treated } & 7.131 & 362034 & 2036 & \multirow{2}{*}{14.5291} & \multirow{2}{*}{4.6585} & \multirow{2}{*}{17.1778} & \multirow[t]{2}{*}{0.090} \\
\hline & 9.292 & 279663 & 1686 & & & & \\
\hline
\end{tabular}

2-theta- Bragg's angle; D- crystallite size; $a, b, c$ - lattice parameters.

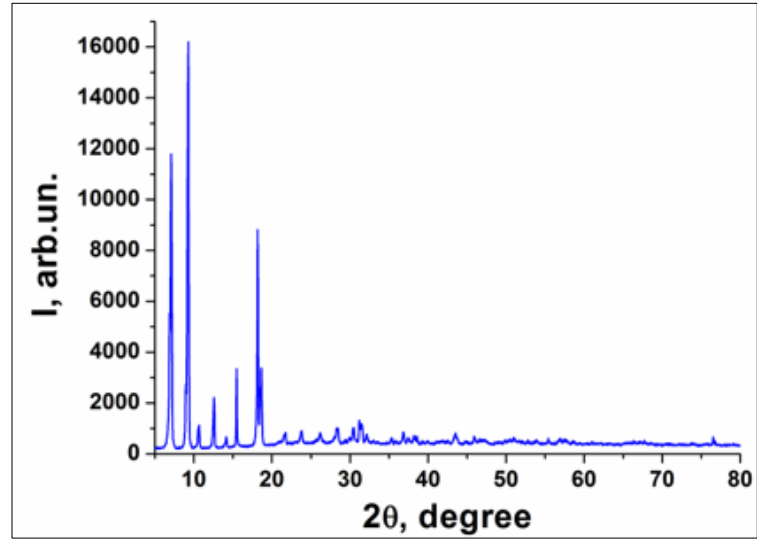

Figure 4. X-ray diffractogram of CuPc powder

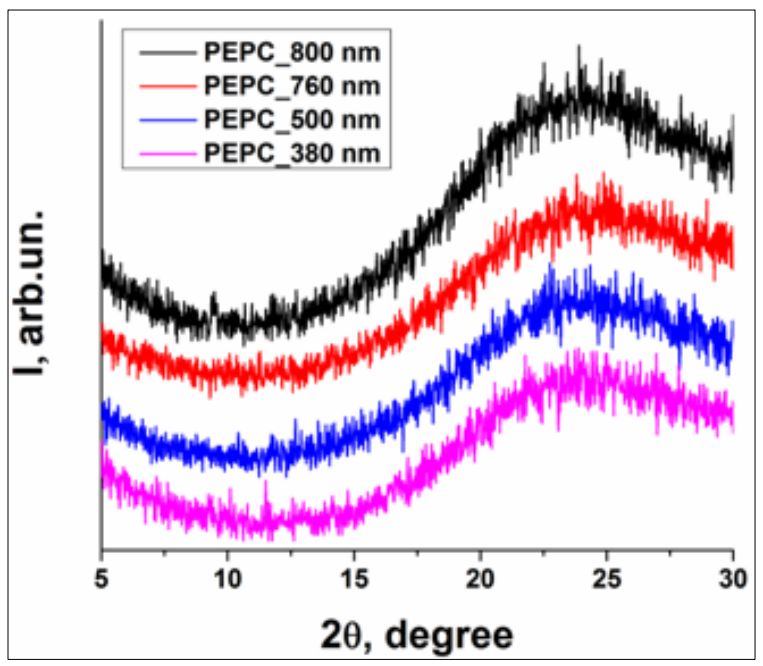

Mater. Plast., 57 (4), 2020, 134-144
Figure 5. X-ray diffractograms of PEPC films with different thicknesses: $380 \mathrm{~nm} ; 500 \mathrm{~nm}$, $760 \mathrm{~nm}$ and $800 \mathrm{~nm}$ 


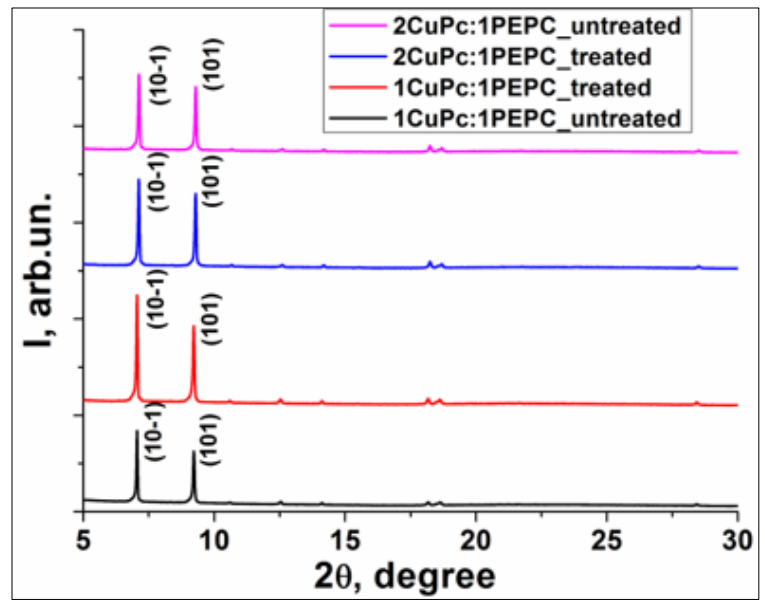

Figure 6. X-ray diffractogram of CuPc:PEPC composite thin films

The polycrystalline films show a larger value of strain indicating more strain on the lattice. The results showed that the crystallite size estimated from Scherer's formula, Williamson-Hall plots and size-strain plot are very well inter-correlated.

Annealing in $\mathrm{H}_{2}$ environment of the $1 \mathrm{CuPc}$ :1PEPC composite thin film decreases crystalline sizes from $214 \mathrm{~nm}$ to $188 \mathrm{~nm}$, while in the case of $2 \mathrm{CuPc}$ : 1 PEPC composite the crystalline size increases from $182 \mathrm{~nm}$ to $204 \mathrm{~nm}$. We suppose that decreasing of crystallite size for $2 \mathrm{CuPc}: 1 \mathrm{PEPC}$ is caused by the increased concentration of $\mathrm{Cu}$ in blend and thermally annealing. Annealing in $\mathrm{H}_{2}$ atmosphere at $60^{\circ} \mathrm{C}$ lead to the intra-grain recrystallization and sintering of the primary crystallites, resulting in the contraction of grains.

\subsection{Optical Properties and Spectral Distribution of Photoconductivity of CuPc:PEPC Composite Thin Films}

The UV-Vis spectra of the optical transmission of the CuPc:PEPC composite thin films are shown in Figure 7. It could be noted that at longer wavelengths $(\lambda>850 \mathrm{~nm})$ all films become transparent. As an effect of annealing, the average optical transmittance of the samples decreases. Figure 8 depicts UVVis absorption spectra of $\mathrm{CuPc}$, PEPC films and CuPc:PEPC composite thin films with different concentration of $\mathrm{CuPc}$ annealed at $60^{\circ} \mathrm{C}$ in $\mathrm{H}_{2}$ atmosphere.

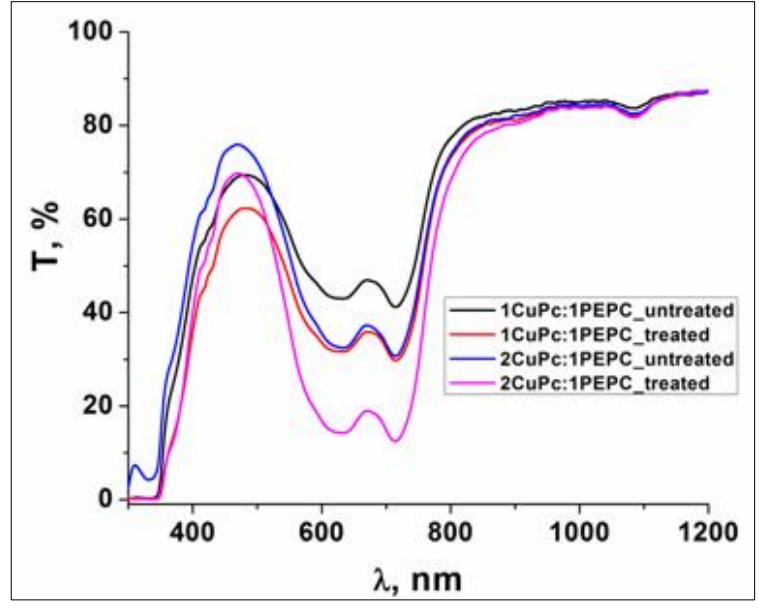

Figure 7. Transmittance of CuPc:PEPC

Composite thin films 
$\mathrm{CuPc}$ thin film show two typical absorption bands, namely the Q band in the visible region (600-800 $\mathrm{nm})$ and the B band or Soret band in the violet or near-ultraviolet region (300-480 nm) with two and one maxima, respectively. The $\mathrm{Q}$ band can be attributed to the allowed highest occupied molecular orbital (HOMO)-lowest unoccupied molecular orbital (LUMO) $\left(\pi-\pi^{*}\right)$ transitions [18]. The presence of this absorption band may be interpreted as an overlap of $\pi$ orbitals through the ligand, where the electrons are able to transfer energy throughout the structure [19]. The Soret band is due to electronic transitions between molecules of an intermediate ionic degree that characterize the synthesized molecular materials or by the ultraviolet absorption band edge of the phthalocyanine moiety [28]. The absorbance spectrum of PEPC shows a wide absorption band in the 280-650 $\mathrm{nm}$ region (Figure 8) with intensive maxima positioned at $345 \mathrm{~nm}$ and a shoulder in the visible region. The extension of the PEPC absorption in the visible region of the spectra is determined by the introduction of 2,4,7-trinitrofluorenone (TNF) into PEPC [17]. To determine the best absorber, different ratios by weight of the two materials were studied. The area under the graph of absorbance represents the total absorbance or amplitude for the given curve.

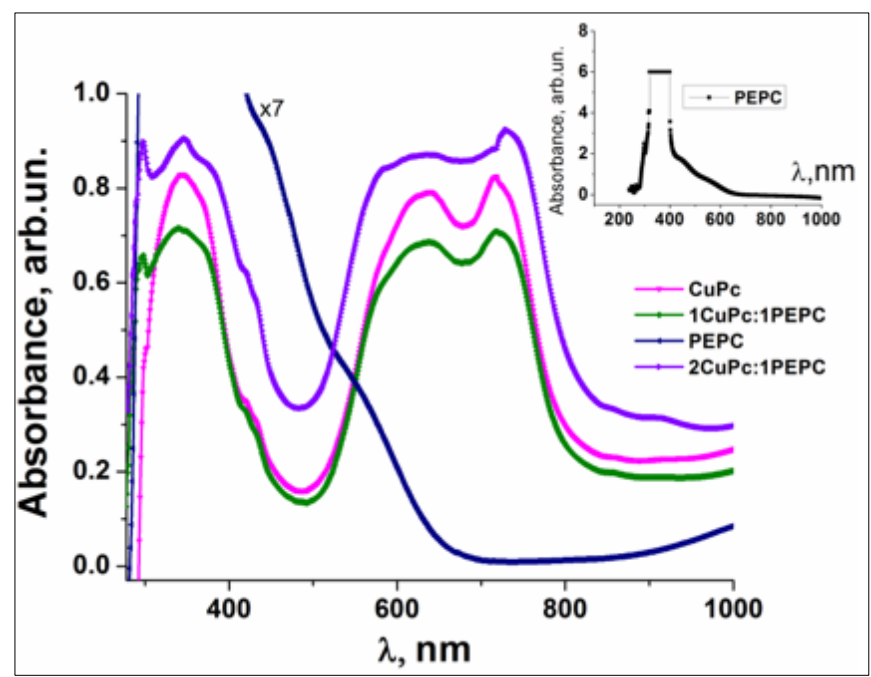

Figure 8. Absorbance of CuPc:PEPC composite thin films. Insert represents the absorbance spectrum of PEPC

In the Figure 8 absorption spectra of CuPc, PEPC films and CuPc:PEPC composite thin films annealed at $60^{\circ} \mathrm{C}$ in $\mathrm{H}_{2}$ atmosphere, with weight ratios $1: 1$ and $2: 1$ are shown. From this investigation, we were able to conclude that, within the investigated range of the blend ratios, the 2:1 ratio is optimum blend ratio. The absorption spectra of CuPc:PEPC composite thin films show two absorption bands, one more intensive and another less intensive than those of pure CuPc. The both, UV and IR bands are wider in comparison with of those of pure CuPc film. In addition, the Soret band has two peaks situated at 297 $\mathrm{nm}$ and $345 \mathrm{~nm}$ that can be attributed to PEPC [17]. A comparison of the evolution of the vibrational modes appearing in conducting polymers and in some simpler related molecules acting as references usually facilitates the interpretation of the experimental absorption spectra. Therefore, Fourier transform infrared spectroscopy (FTIR) was employed to investigate possible changes in the intra-molecular bonds. FTIR showed that the main spectral features distinguishing the CuPc: PEPC dissolved in clorobenzen and CuPc:PEPC dissolved in mixed clorobenzen and TNF solvents are the bands situated at $874.1 \mathrm{~cm}^{-1}, 1284.7 \mathrm{~cm}^{-1}$ and $1782.1 \mathrm{~cm}^{-1}$ (Figure 9). These bands are attributed to the $\mathrm{CuPc}$ and oxidation product of copper phthalocyanine. The observable spectral features in FTIR spectra of CuPc:PEPC composite allow us to conclude, that partial transfer of electron donor from PEPC into $\mathrm{CuPc}$ and electron acceptor from $\mathrm{CuPc}$ into PEPC broadens the absorbance bands. PEPC and $\mathrm{CuPc}$ create charge-transfer complexes. Due to the formation of the PEPC-CuPc complex, the resistivity of the composite also decreases and allows measuring the spectral distribution of photoconductivity. 


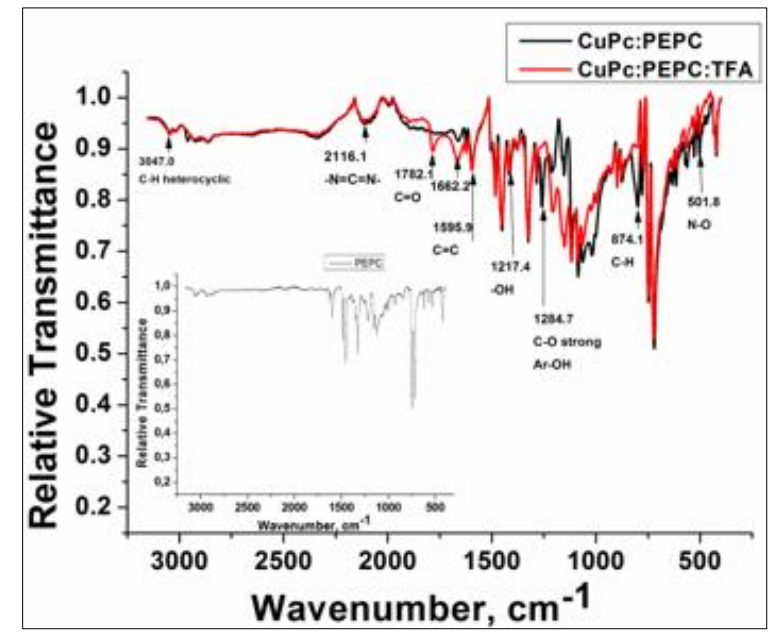

Figure 9. FTIR spectra of $\mathrm{CuPc}: \mathrm{PEPC}$ and CuPc:PEPC:TFA composite thin films. Insert: FTIR spectra of PEPC thin film

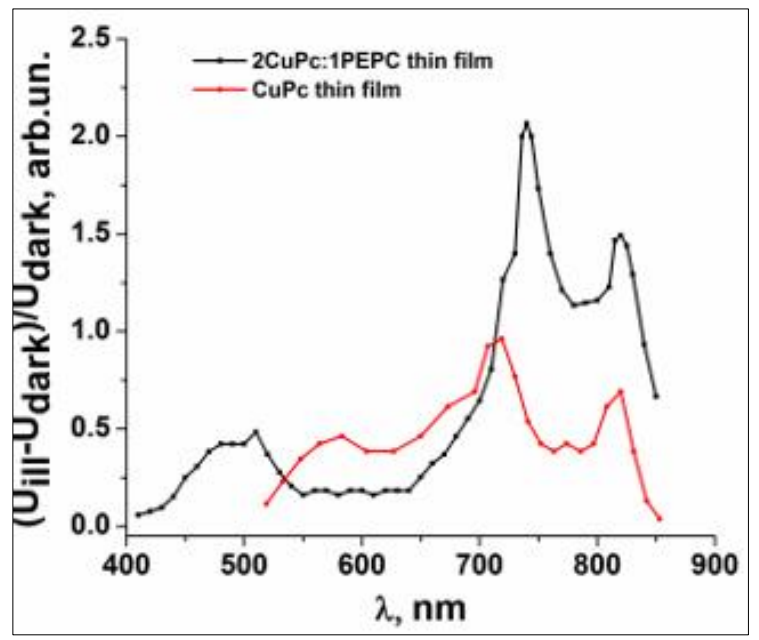

Figure 10. The spectral distribution of photoconductivity-absorption of $\mathrm{CuPc}$ thin film and 2CuPc:1PEPC composite thin film

Figure 10 shows the spectral distribution of photoconductivity-absorption of CuPc thin film and $2 \mathrm{CuPc}: 1 \mathrm{PEPC}$ composite thin films. It is obvious from this figure that $\mathrm{CuPc}$ film and $2 \mathrm{CuPc} 1 \mathrm{PEPC}$ composite thin film are photosensitive in the range of 420-850 nm with the maximum in near IR-region close to the region with maximal solar photons flux $(700-800 \mathrm{~nm})$. An increase in photoconductivity is more pronounced for $2 \mathrm{CuPc}$ :1PEPC composite film. Besides this, a shift in the IR and UV regions is observed. It is assumed that the photoconductivity is associated with polarization due to partial transfer of photo-generated acceptors $(\mathrm{CuPc})$ and donors (PEPC) that significantly depend on the nature of low molecular impurities $(\mathrm{CuPc})$ and also, on their doping concentration in the polymer. Due to the formation of the PEPC-CuPc complexes the resistivity of the composite decreases, that allows the photoconductivity to increase. 


\subsection{Photovoltaic devices based on CuPc:PEPC composite thin films}

For the fabrication of the photovoltaic devices were used PEPC prepared by Moldova State University and $\mathrm{CuPc}$ purchased from Sigma-Aldrich. PEPC is an electron donor, but CuPc act as an electron acceptor. The bulk heterojunction solar cells reported here were prepared by drop casting of CuPc:PEPC composite thin films on the ITO glass substrates purchased from Solaronix Swiss. To finish the device, $200 \mathrm{~nm}$ of $\mathrm{Al}$ was deposited by thermal evaporation. The schematic diagram of the ITO/CuPc:PEPC/Al photovoltaic device is illustrated in Figure 11(a). The J-V characteristics under illumination of AM1.5 $\left(100 \mathrm{~mW} \cdot \mathrm{cm}^{-2}\right)$ are shown in Figure 11(b). As one can see from figure the open circuit voltage (Voc) and the short circuit current density (Jsc) depend on the composition of the $\mathrm{CuPc}$ :PEPC blend. When CuPc predominate in the blend, the Voc is higher. The annealing of the device at the temperature higher than $200^{\circ} \mathrm{C}$ deteriorates the device (curve 4). The FF defined as the ratio of the maximum power from the solar cell to the product of Voc and Jsc has small values of about $0.3 \ldots 0.33$. The low values of FF are due to the series/shunt resistances. The smaller value than $1 \%$ of power conversion efficiency is caused by not only small values of FF and Jsc but may be also due to inefficient exciton dissociation and non-radiative recombination losses.

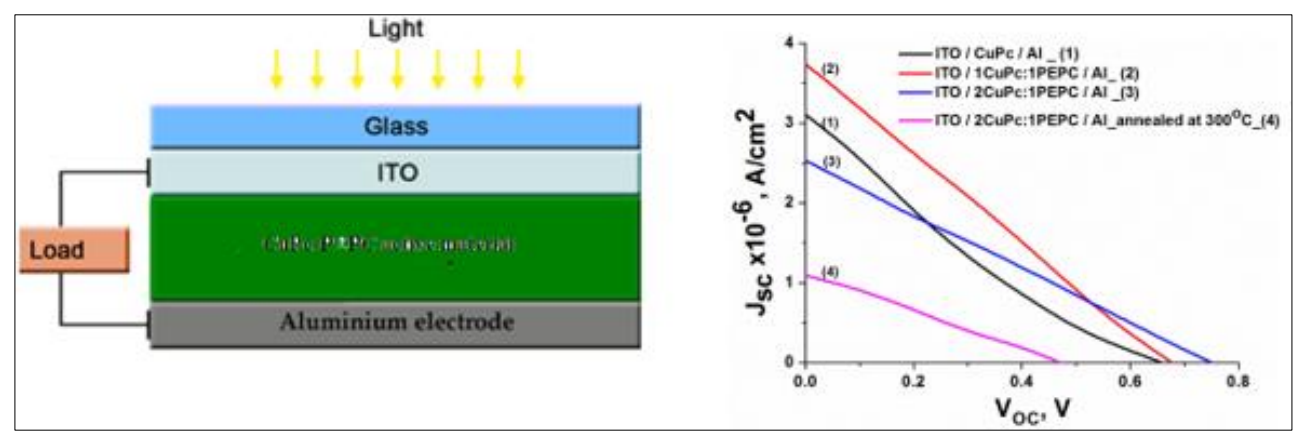

Figure 11. The schematic diagram (a) and the J-U characteristics under illumination of AM1.5 solar simulation $\left(100 \mathrm{~mW} \mathrm{~cm}^{-2}\right)$ of the ITO/CuPc:PEPC /Al photovoltaic devices (b)

\section{Conclusions}

The CuPc:PEPC composite thin films were prepared by drop casting method. The key results are outlined as follows:

-the diffraction patterns of the CuPc:PEPC composite thin films reveal good crystallinity and the beta-copper phthalocyanine phase;

- XRD analysis of PEPC films shows higher amorphous character with broader peak;

-study of the EDAX of CuPc:PEPC thin film composites indicates an increase in $\mathrm{Cu}$ by three times with increasing content of $\mathrm{CuPc}$ in the blend.

-the CuPc:PEPC composite thin films was found to improve the absorption characteristics of $\mathrm{CuPc}$, especially after annealing in hydrogen atmosphere. The investigation of the optical properties of CuPc:PEPC composite thin films indicate that the absorption spectrum in the deep ultraviolet and visible region consists of two broader $\mathrm{B}$ and $\mathrm{Q}$ bands respectively, both with two peaks which can be attributed to the formation of charge-transfer complexes

-the composite thin films are photoconductive in the range 420-850 $\mathrm{nm}$ with one maximum in the (400-550) $\mathrm{nm}$ region and other two maxima in near IR-region close to the region with maximal solar photons flux (700-800).

The power conversion efficiency of ITO/CuPc:PEPC/Al photovoltaic device is very modest but can be improved by using (hole transport layer) HTL and electron transport layer (ETL) buffer layers. 
Acknowledgements: The Ministry of Education, Culture and Research of Republic of Moldova supported this research by the National Grant 20.80009.5007.16.

\section{References}

1.YU, G., GAO, J., HUMMELEN, J. C., WUDL, F., HEEGER, A. J. Polymer Photovoltaic Cells: Enhanced Efficiencies via a Network of Internal Donor-Acceptor Heterojunctions, Science, 270, 1995, 1789.

2.GUNES, S., NEUGEBAUER, H.S., SARICIFTCI, N.S. Conjugated Polymer-Based Organic Solar Cells, Chem. Rev., 107, 2007, 1324-1338 (2007).

3.COAKLEY, K., MCGEHEE, M.D. Conjugated polymer photovoltaic cells, Chem. Mater., 16, 2004, 4533.

4.LI, C., LIU, M., PSCHIRER, N.G., BAUMGARTEN, M., MÜLLEN, K. Polyphenylene-based materials for organic photovoltaics, Chem. Rev., 110, 2010, 6817.

5.SILVESTRI, F., MARROCCHI, A., Int. Acetylene-Based materials in organic photovoltaics, J. Mol. Sci., 11, 2010, 1471.

6.ZHANG, F., WU, D., XU, Y. FENG, X. Thiophene-based conjugated oligomers for organic solar cells, J. Mater. Chem., 21(44), 2011, 17590.

7.CHOCHOS, C.L., CHOULIS, S.A. How the structural deviations on the backbone of conjugated polymers influence their optoelectronic properties and photovoltaic performance, Prog. Polym. Sci., 36(10), 2011, 1326.

8.ZHOU, H., YANG, L., YOU, W. Rational design of high performance conjugated polymers for organic solar cells, Macromolecules, 45(2), 2012, 607.

9.PRICE, S. C., STUART, A. C., YANG, L., ZHOU, H., YOU, W. Fluorine substituted conjugated polymer of medium band gap yields $7 \%$ efficiency in polymer- fullerene solar cells, J. Am. Chem. Soc., $133,2011,4625$.

10.ZHOU, H., YANG, L., STUART, A. C., PRICE, S. C., LIU, S., YOU, W. Development of fluorinated benzothiadiazole as a structural unit for a polymer solar cell of $7 \%$ efficiency, Angew. Chemie Int. Ed., 50(13), 2011, 2995.

11.LIANG, Y. Y., XU, Z., XIA, J. B., TSAI, S.-T. T., WU, Y., LI, G., RAY, C. YU, L. P. For the bright future-bulk heterojunction polymer solar cells with power conversion efficiency of $7.4 \%$, Adv. Mater., 22(20), 2010, 135.

12.LIU, Y., ZHAO, J., LI, Z., MU, C., MA, W., HU, H., JIANG, K., LIN, H., ADE, H., YAN, H. Aggregation and morphology control enables multiple cases of high-efficiency polymer solar cells, Nat. Commun., 5, 2014, 5293.

13.ACHIBA, Y., NAKAGAWA, T., MATSUI, Y., SUZUKI, S., SHIROMARU, H., YAMAUCHI, K., NISHIYAMA, K., KAINOSHO, N., HOSHI, H., MARUYAMA, Y., MITANI, T. Ultraviolet photoelectron spectra of C76 and KxC76, Chemistry Letters, 1991, 1233.

14.BANSAL, S., KUMAR, N. C60 and C70 electronic absorption spectra in different solvents and matrices, J. Biomed Nanotechnol., 7(1), 2011, 199-201.

15.LEZNOFF, C. C., LEVER, A. B. P. Phthalocyanines: Properties and Applications, New York, 1993. 16.KUVSHINSKY, N.G., DAVIDENKO N.A. \& RESHETNYAK V.V. On the influence of electron localization radius in a charge-transfer complex on photogeneration efficiency of current carriers in carbazole-containing semiconductors, Molecular Physics, 69, (5), 1990, 933-941.

17.GAIDELIS, V., KRIITJNAS, V., MONTRIMAS, E. Optical and photoelectric properties of thin layers of poly-n-epoxypropylcarbazole, Thin Solid Films, 38, 1976, 9.

18.KUMAR, G. A., THOMAS, J., UNNIKRISHNAN, N. V., NAMPOORI V.P.N., VALLABHAN, C.P.G. Optical absorption and emission spectral studies of phthalocyanine molecules in DMF, Journal of Porphyrins and Phthalocyanines, 5, 2001, 456. 
19.PRABAKARAN, R., KESAVAMOORTHY, R., REDDY, G. L. N., XAVIER, F. P. Structural Investigation of Copper Phthalocyanine Thin Films Using X-Ray Diffraction, Raman Scattering and Optical Absorption Measurements, Phys Stat Sol (b), 229(3), 2002, 1175.

20.CHAKAROUN, M., LUCAS, B., RATIER, B., ALDISSI, M. ITO/Au/ITO Multilayer Electrodes for CuPc/C60 Solar Cells, Energy Procedia, 31, 2012, 102.

21.SALEEM, M., SAYYAD, M. H., KARIMOV, KH. S., YASEEN, M., ALI, M. Surface-type multifunctional sensor based on 5, 10, 15, 20-tetrakis (4'-isopropylphenyl) porphyrin, J. Mater. Sci., 44, 2009, 1192.

22.SALEEM, M., SAYYAD, M. H., KARIMOV, K. S., AHMAD, Z., SHAH, M., YASEEN, Y., KHOKHAR, I., ALI, M. Synthesis and photocapacitive studies of Cu (II) 5, 10, 15, 20-tetrakis (4'isopropylphenyl) porphyrin, J. Optoelectron. Adv. Mater., 10(6), 2008, 1468.

23.KARIMOV, KH. S., CHEONG, K. Y., SALEEM, M., MURTAZA, I., FAROOQ, M., NOOR, A. F. $\mathrm{Ag} / \mathrm{PEPC} / \mathrm{NiPc} / \mathrm{ZnO} / \mathrm{Ag}$ thin film capacitive and resistive humidity sensors, J. Semicond, 31(5), 2010, 054002.

24.BORDIAN, O., CULEAC, I., IOVU, M., VERLAN, V., POPUSOI, A., POPUSOI, M., ROBU, ST., DRAGALINA, G., ŞEPELI, D. Technology and some optical proprieties of nanocomposites PEPC/CuPc, Moldavian Journal of the Physical Sciences, 12(3-4), 2013, 229.

25.SHRESTHA, N.K., KOHN, H., IMAMURA, M., IRIE, K., OGIHARA, H., SAJI, T. Electrophoretic deposition of phthalocyanine in organic solutions containing trifluoroacetic acid, Langmuir, 26 (22), 2010, 17024.

26.IAN L., ZHANG J., XUE M., ZHU Y., ZHANG Q., LIU Y. Dissolving and Electro-Chemical Deposition of Copper Phthalocyanine, Imaging Science and Photochemistry, 29(2), 2011, 114.

27.JUNGYOON, E., SUNMI K., LIM, E., LEE, K., CHA, D. Effects of substrate temperature on copper (II) phthalocyanine thin films, Barry Friedman, Applied Surface Science, 205, 2003, 274.

28.SŁOTA, R., DYRDA, G. UV photostability of metal phthalocyanines in organic solvents, Inorg Chem., 42(18), 2003, 5743.

Manuscript received: 2.10 .2020 